\title{
Is news related to GDP growth a risk factor for commodity futures returns?*
}

\author{
Daniel Tsvetanov ${ }^{\dagger} \quad$ Jerry Coakley ${ }^{\ddagger} \quad$ Neil Kellard ${ }^{\S} \ddagger$
}

This version: June 23, 2016

\begin{abstract}
Expectations about future economic activity should theoretically affect the demand for inventory holdings and therefore commodity spot and futures prices. Consistent with these predictions, we find that news related to future GDP growth is a significant factor that is priced in the cross-section of commodity futures sorted by percentage net basis. The latter is highly correlated with inventories. In particular, it establishes that commodity futures with high inventory levels provide a hedge against risk associated with future GDP growth so that investors are willing to accept lower return. By contrast, those commodity futures with low inventory levels are inversely related to the GDP-related factor so that investors require a higher return. Such results suggest that commodity futures excess returns are a compensation for risk.
\end{abstract}

JEL Classification: G12, G13.

Keywords: Commodity futures, Percentage net basis, Asset pricing, News, Gross domestic product.

\footnotetext{
${ }^{*}$ We are grateful to the special issue editor Dr Georgios Sermpinis and the anonymous referees for helpful and constructive comments on an earlier version of this paper. We also gratefully acknowledge support from grant number ES/L011859/1, from the Business and Local Government Data Research Centre, funded by the Economic and Social Research Council.

${ }^{\dagger}$ Business and Local Government Data Research Centre, University of Essex, Colchester, CO4 3SQ, UK

${ }^{\ddagger}$ Business and Local Government Data Research Centre and Essex Business School, University of Essex, Colchester, CO4 3SQ, UK

${ }^{\S}$ Corresponding author. Email: nkellard@essex.ac.uk
} 


\section{Introduction}

The Theory of Storage (see, Kaldor, 1939; Working, 1949; Brennan, 1958) defines commodity futures prices in terms of carrying costs and benefits of holding the commodity rather than the futures contract. By contrast, the Theory of Normal Backwardation of Keynes (1930) and Hicks (1939) suggests that expected futures returns consist only of a risk premium paid by producers and inventory holders in order to hedge their exposure to future spot price risk. While these two views have long been subject of academic research, the empirical results are still mixed and inconclusive. The goal of this paper is to make an empirical contribution to this literature. Using a broad cross-section of 26 commodity futures over the period from December 1969 to December 2012 we show in a standard linear asset pricing framework that risk can explain aspects of commodities as well as stocks' behaviour.

The net benefits of holding a commodity are typically referred to as the convenience yield and this is analogous to the dividend on a stock. Thus, similar to the dividend-price ratio in the equity literature, one can attribute the variation in the percentage net basis (net convenience yield to price ratio) to the variation in expected yield growth and/or expected excess returns. Consistent with this decomposition, we find that sorting commodity futures contracts on the percentage net basis results in portfolio average excess returns that are monotonically increasing. Furthermore, shorting commodity futures with the lowest percentage net basis and buying those with the highest percentage net basis results in an abnormal average excess return of around $18 \%$ per annum over the sample period. In the context of Merton's (1973) Intertemporal Capital Asset Pricing Model (ICAPM), we show that these abnormal returns can indeed be understood as a compensation for risk.

Several studies examine the pricing of traditional risk factors in commodity futures (see, inter alios, Daskalaki, Kostakis, and Skiadopoulos, 2014; Dusak, 1973; Jagannathan, 1985) but find their covariance with futures pay-offs to be statistically insignificant. The first and main contribution of this paper is that it addresses this question from a new perspective that provides novel insights on the pricing of commodity futures. As a point of departure, while the level of inventories may be a key determinant of expected commodity futures returns, it may equally reflect the expectations of producers and inventory holders about future economic activity or GDP (Gross Domestic Product) growth. Guided by this insight, we test whether news related to future GDP growth is a priced risk factor in the cross-section of commodity futures returns.

The testing approach follows Vassalou (2003) in creating a mimicking portfolio using the return from the sorted futures portfolios and two fixed-income portfolios. ${ }^{1}$ As Cochrane (2005)

\footnotetext{
${ }^{1}$ Note that Vassalou (2003) investigates the role of news about future GDP growth as a risk factor in the cross
} 
notes, the factor-mimicking portfolio contains the same pricing information as the state variable of interest and can be used as a hedging or profiting tool. The empirical findings suggest that commodity futures characterized by a high percentage net basis have negative exposure to the GDP-related factor, whereas those with a low percentage net basis have positive exposure. ${ }^{2}$ That is, investors are ready to accept low returns on portfolios of futures with low percentage net basis since they provide a hedge against risk associated with future GDP growth, but demand high returns on portfolios of futures with high percentage net basis. These novel results follow from a stochastic discount factor approach and lead to the conclusion that portfolio excess returns are a compensation for risk. This result is in line with Frankel (2014) who argues that expectations of higher economic activity should have a positive effect on the demand for inventories and thus on commodity spot and futures prices.

The main implications of our asset pricing test are closely related to recent studies in the literature. Gorton, Hayashi, and Rouwenhorst (2013) investigate the effect of inventories on the variation of expected commodity futures returns and show empirically that state variables like the basis, prior futures returns, and spot price volatility are related to the level of inventories and the risk premiums. However, in contrast to our study, their analysis is not concerned with the determinants of inventory holdings and how these determinants affect futures prices. Yang (2013) follows the recent trend in the currency market literature and adopts a datadriven approach to identify a slope factor, which represents the return difference between the highest and lowest portfolios sorted on the basis (HML). He finds that this factor is successful in explaining the cross-sectional variations of the basis sorted portfolio excess returns and it is highly correlated with investment shocks, which represents technological progress in producing new capital. In contrast to his study, this study finds that the GDP-related factor has a correlation of about $-41 \%$ with the analogous slope factor from the percentage net basis sorted portfolios. Therefore, it does not substitute one factor with an identical factor. Instead it shows that the orthogonalized component (with respect to the GDP-related factor) of the HML portfolio is not priced when it is jointly included with the (GDP growth) factor-mimicking portfolio, whereas the latter is highly significant.

The paper's second contribution is that our empirical findings indirectly shed light on the literature that investigates the overarching question of whether commodities are distinctive or their risk-return profile is similar to stocks. ${ }^{3}$ Vassalou (2003) finds the same macroeconomic

\footnotetext{
section of equity returns.

${ }^{2}$ The theory predicts that the convenience yield is a convex function of inventories, i.e. it declines as the level of inventories decreases (see Ng and Pirrong, 1994, and references therein). Therefore, commodities characterized by low percentage net basis are associated with high level of inventories and vice versa.

${ }^{3}$ Fernandez-Perez, Fuertes, and Miffre (2015) establish that commodity portfolios that capture the backwardation and contango phases exhibit predictive power for aggregate equity market returns. See also Bessembinder
} 
variable to be a significant factor that explains the cross-section of equity returns. Therefore, in this sense, commodity futures and stock markets share similar risk characteristics, suggesting a degree of market integration. To our knowledge, this is the first study to establish such a finding.

The rest of the paper is organized as follows. In Section 2, we provide a decomposition of commodity futures returns using a rational no-bubble framework. Section 3 describes the data and the construction of the commodity futures portfolios. Section 4 offers a risk-based explanation of the returns. In Section 5, we discuss the empirical results from the cross-sectional asset pricing test. Section 6 provides robustness results of our findings considering alternative portfolios. Finally, Section 7 concludes.

\section{The decomposition of commodity returns}

In arbitrage equilibrium, the contemporaneous relationship between the futures price of a commodity $F_{t}^{(\tau)}$ at time $t$ for delivery at $t+\tau$ and the spot price $S_{t}$ can be summarised as:

$$
F_{t}^{(\tau)}-S_{t}=R_{t}^{(\tau)} S_{t}-C_{t+\tau}
$$

where $R_{t}^{(\tau)}$ is the risk-free $\tau$ period interest rate, $C_{t+\tau}$ is the net (of storage costs) convenience yield. It can be seen from (1) that the extent to which the discounted futures price,

$F_{t}^{(\tau)} /\left(1+R_{t}^{(\tau)}\right)$, deviates from the spot price depends on the magnitude of the net convenience yield. If it is large and positive, the futures price is lower than the spot price and, in this case, the futures market is said to be in strong backwardation. Keynes (1930) and Hicks (1939) stress that backwardation is indeed a normal condition and the price of the futures contract appreciates as it comes closer to maturity because of a risk premium. The commodity producers and inventory holders take short positions in the futures market to hedge their exposure to future spot price risk. Since they are more risk-averse than their counterparts (usually referred to as speculators), they sell the contract at a discount to the expected future spot price, which represents the premium. These two views have long been at the centre of academic debate and have been separated into two different strands of the literature - the Theory of Storage and the Theory of Normal Backwardation. Following Pindyck (1993), the main features of both of these theories can be combined to derive testable implications for the cross-section of commodity returns.

Consider an investment in a unit of commodity that is held from time $t$ to $t+1$ and sold (1992), Bessembinder and Chan (1992), Erb and Harvey (2006), Gorton and Rouwenhorst (2006). 
for price $S_{t+1}$. The expected return on this investment is given by:

$$
h_{t+1}=\frac{E_{t}\left[S_{t+1}-S_{t}+C_{t+1}\right]}{S_{t}}
$$

where $E_{t}$ denotes the expectations operator conditional on the information at time $t$. Because of uncertainty about the spot price at time $t+1$, assume that the expected return can be written as $h_{t+1}=\pi_{t+1}+R_{t}^{(1)}$, where $\pi$ is a risk premium. One can use (1) and (2) to show that:

$$
E_{t}\left[S_{t+1}\right]=\pi_{t+1} S_{t}+F_{t}^{(1)}
$$

Consistent with the Theory of Normal Backwardation, this equation suggests that the futures price is a biased predictor of the future spot price and the bias is equal to the expected premium. It is straightforward to show from (3) that the payoff to a strategy where an investor goes long a one month futures contract and holds it to delivery is:

$$
S_{t+1}-F_{t}^{(1)}=S_{t+1}-E_{t}\left[S_{t+1}\right]+\pi_{t+1} S_{t}
$$

Fama and French (1987) show empirically that the futures-spot differential (or spread) in (1) is informative about the payoff in (4). This is intuitive since both of them are related to the expected premium, but only the spread is observable at time $t$.

Solving (2) for $S_{t}$, iterating forward, and imposing the transversality condition yields the present value model for commodities where changes in spot prices are explained by changes in fundamentals:

$$
S_{t}=E_{t}\left[\sum_{j=0}^{\infty}\left(\prod_{k=0}^{j}\left(\frac{1}{1+h_{t+k+1}}\right)\right) C_{t+j+1}\right] .
$$

One can relate the variation in percentage net basis (net convenience yield to spot price ratio) to the variation in risk premia using the present value model and the log-linear approximation of Campbell and Shiller (1988). However, during periods of high inventories, the net convenience yield can be negative and the logarithm will not be defined. To take this into account, we again follow Pindyck (1993) and work with the arithmetic ratio $z_{t} \equiv C_{t} / S_{t}$. Specifically, in the Appendix it is shown that the normalized percentage net basis is informative about the future yield growth and expected returns:

$$
z_{t}^{\prime} \approx E_{t}\left[\sum_{j=0}^{\infty} \rho^{j}\left(\rho h_{t+j+1}-\Delta C_{t+j+1}^{\prime}\right)\right]
$$

where $\rho$ is a number close to one, $z_{t}^{\prime}=z_{t} / \bar{z}$, and $C_{t}^{\prime}=C_{t} / \bar{C} . \bar{C}$ and $\bar{z}$ are the sample means of 
$C$ and $z$, respectively. Assuming that the riskless rate is constant over time, (6) becomes:

$$
z_{t}^{\prime} \approx E_{t}\left[\sum_{j=0}^{\infty} \rho^{j}\left(\rho \pi_{t+j+1}-\Delta C_{t+j+1}^{\prime}\right)\right]+\frac{\rho R}{1-\rho} .
$$

Equation (7) is an alternative representation of (5) and suggests that the magnitude of $z_{t}$ depends either on the size of the risk premium or the yield growth. Since both of these components are determinants of commodity futures prices under the Theory of Storage and Theory of Backwardation, the percentage net basis is a natural candidate for predicting the cross-section of expected commodity futures returns. Sorting commodity futures into portfolios using this variable should result in a significant spread of average portfolio returns (see, e.g., Gorton, Hayashi, and Rouwenhorst, 2013; Szymanowska, de Roon, Nijman, and van den Goorbergh, 2014).

\section{Data and commodity futures portfolios}

Daily settlement prices on 26 commodity futures are obtained from Commodity Research Bureau (CRB) over the period December 1969 to December 2012. Commodity futures are categorised into five sectors: agricultural, energy, animal products, metals, and wood. ${ }^{4}$ The agricultural sector consists of cocoa, coffee, corn, cotton, oats, orange juice, rough rice, soy meal, soy oil, soybeans, sugar and wheat. The energy sector contains four commodity futures: crude oil, gasoline, heating oil and natural gas. Animal products comprise feeder cattle, lean hogs, live cattle, and milk, whereas coal, copper, gold, platinum, and silver, are classified as metals. The wood sector consists of lumber.

End-of-month values are obtained from daily settlement prices to calculate returns on monthly futures as the percentage change in the price of the contract with nearest delivery. ${ }^{5}$ The resulting series correspond to the realized return by a trader that maintains a long position in the nearest futures contract, rolling to the second nearest at the last business day of the month prior to maturity. ${ }^{6}$ Following this procedure, the return series are constructed using successive prices on a contract with a given maturity.

We infer the net convenience yield using (1), the price of futures with three months to maturity (as closely as possible), and the three month Treasury bill as a proxy for the risk free

\footnotetext{
${ }^{4}$ We use a classification similar to that used by Fama and French (1987).

${ }^{5}$ The choice of discrete returns is in line with Gorton, Hayashi, and Rouwenhorst (2013) and Yang (2013). It also allows us to avoid the assumption of joint log-normality of futures excess returns and the stochastic discount factor described in Section 4. In addition, the choice of simple returns will be useful when constructing the portfolios, since linear returns are additive across assets.

${ }^{6}$ We concentrate the analysis on the nearest futures contract because they are the most liquid (e.g., Chan, 1992; Fleming, Ostdiek, and Whaley, 1996; Ergün, 2009).
} 
rate. $^{7}$ Because spot prices of commodities are not directly comparable to futures prices (e.g. Pindyck, 1993), a common practice in the literature is to approximate the spot price, $S_{t}$, by the price of the nearest futures contract. However, one problem is that most commodity futures in our sample do not trade for delivery in every month and the nearest contract might have few months until expiration. In such case the price of this contract might not be a good proxy for the cash price. Therefore, we follow Pindyck $(1993,2001,2004)$ and extrapolate the spot price from the price of the nearest and second nearest futures contracts:

$$
S_{t}=F_{t}^{(1)}\left(\frac{F_{t}^{(1)}}{F_{t}^{(2)}}\right)^{\frac{\tau_{1}}{\tau_{2}-\tau_{1}}}
$$

where $\tau_{1}$ is the number of days to the expiration of the nearest contract, $F_{t}^{(1)}$, and $\tau_{2}$ is the number of days to the expiration of the next-to-nearest contract, $F_{t}^{(2)}$.

We follow the literature and construct portfolios by sorting the futures into five bins to capture the informational content of the percentage net basis. This sorting approach was introduced in the finance literature by Fama and French (1993) and has recently been applied in the currency and commodity literature (see, inter alios, Lustig and Verdelhan, 2007; Menkhoff, Sarno, Schmeling, and Schrimpf, 2012; Yang, 2013; Szymanowska, de Roon, Nijman, and van den Goorbergh, 2014). The strategy is implemented as follows. At the end of month $t$ we rank available commodities based on the percentage net basis. The lowest percentage net basis quintile of commodities is allocated to portfolio $P 1$, the next to portfolio $P 2$, and so on up to portfolio $P 5$, which contains the highest percentage net basis quintile. This decomposition is held until the end of month $t+1$. The return on each portfolio is calculated as an equallyweighted average of the composite futures excess returns. We follow this strategy each month until the end of the sample. We also consider two other portfolios. One is an equally-weighted average long only position in all five portfolios and is denoted by EWA. The other is a longshort portfolio denoted as HML, where a long position in portfolio $P 5$ is combined with a short position in portfolio $P 1$. Descriptive statistics for these seven portfolios are provided in Table 1, Panel A.

\section{[Table 1 around here]}

There is a clear pattern of monotonically increasing (annualized) average excess returns as from portfolio $P 1$ to portfolio $P 5$. These results are consistent with the theoretical analysis in the previous section where we argue that the net percentage basis is informative about the commodity futures risk premium. Although, there is no clear pattern in the standard deviation,

\footnotetext{
${ }^{7}$ The three month Treasury bill rate is obtained from the database of the Federal Reserve Bank of St. Louis (FRED).
} 
the Sharpe ratios (SR) are also monotonically increasing, indicating that the excess return per unit of risk is higher for commodities with high percentage net basis. Skewness and excess kurtosis exhibit a convex pattern with the lowest values for portfolio $P 3$, while the conditional return distribution for the two corner portfolios, $P 1$ and $P 5$, is significantly more peaked and positively skewed relative to the normal distribution.

The perceived significant spread in the average excess returns of the five portfolios suggests that the percentage net basis is a good state variable for strategic asset allocation. The (annualized) average excess return from the self-financing strategy (HML) is almost 4 times higher than the EWA strategy. The HML strategy also offers much better risk-adjusted performance with a SR more than double that of the equally weighted average portfolio and half of its excess kurtosis. The performance of this long-short strategy also compares favourably with the US stock market. The (annualized) excess return on the S\&P500 index over the same period is around $3 \%$ with an SR of 0.2 .

The next section provides a risk-based explanation of the returns to the percentage net basis portfolios and considers the importance of risk factors that are available at the quarterly frequency. We thus compute quarterly excess returns of the above portfolios by compounding the three monthly excess returns for each quarter. Summary information about the performance of all portfolios at quarterly horizons is provided in Table 1, Panel B. The results are similar to those reported in Panel A and the conclusions remain the same.

\section{A risk based explanation of the expected returns}

Cochrane (2005) stresses that, in arbitrage equilibrium where investors have concave utility, there is a pricing kernel $M$ (or stochastic discount factor, SDF) that prices all payoffs, such that:

$$
E\left[R_{i}^{e} M\right]=0,
$$

where $R_{i}^{e}$ is the excess return of portfolio $i(=1, \ldots, 5)$. An alternative representation of (9) that follows immediately from the definition of covariance is:

$$
E\left[R_{i}^{e}\right] E[M]+\operatorname{cov}\left[R_{i}^{e}, M\right]=0 .
$$

While (9) provides insights for a risk based explanation of conditional risk premiums, the main challenge in the empirical literature is the identification of a stochastic discount factor that is correlated with the returns.

A traditional approach in the asset pricing literature is to specify the SDF as a linear func- 
tion of one or several factors. Recently, Yang (2013) investigates the covariance structure of commodity futures portfolios sorted on the basis and finds that the first two principal components account for almost $75 \%$ of the variation in the time series of portfolio returns. The first of these two components is highly correlated with the analogous EWA portfolio, while the second component is highly correlated with the analogous HML portfolio. Hence, these factors ought to price the sorted portfolios by construction.

We offer a risk-based explanation of commodity futures returns from a different angle. Gorton, Hayashi, and Rouwenhorst (2013) argue that physical inventories are a key determinant in the cross-sectional variation of expected commodity futures returns. Frankel (2014) stresses that expected changes in future economic activity have a direct effect on the current demand for inventories. Motivated by these insights, we test whether news related to future GDP growth can rationalize the excess returns of the five futures portfolios sorted on the percentage net basis. Consistent with the recent literature on asset pricing, the SDF used in our empirical work is given by:

$$
M_{t}=1-b_{1}\left(R_{E W A, t}-\mu_{R_{E W A}}\right)-b_{2}\left(R_{G D P, t}-\mu_{R_{G D P}}\right),
$$

where $R_{E W A, t}$ is the return of the EWA portfolio, $R_{G D P, t}$ is the return of the GDP-related factor, $b_{1}$ and $b_{2}$ are the SDF parameters (factor loadings), and $\mu_{X}$ is the mean of $X$.

Since we consider news rather than expectations about GDP growth as a risk factor in the cross-section of futures excess returns, we follow Vassalou (2003) and use a mimicking portfolio to extract the information from the futures returns. In particular, we regress GDP growth four quarters ahead on the current quarter excess returns of the five futures portfolios, the default spread $(D E F)$, and the term spread (TERM):

$$
G D P G_{t+4}=c_{0}+\sum_{i=1}^{5} c_{i} R_{i, t}^{e}+c_{6} D E F_{t}+c_{7} T E R M_{t}+\epsilon_{t+4} .
$$

We obtain seasonally adjusted real GDP data for the period 1971:Q1 to 2013:Q4 from FRED. $D E F$ is defined as the difference between the return of long-term corporate and long term government bonds. TERM is the difference between the yields of a long term government bond and a 3-month Treasury bill. We use the data for DEF and TERM from Amit Goyal's website. $^{8}$

The return of the factor mimicking portfolio is defined as $R_{G D P, t}=\sum_{i=1}^{5} \hat{c}_{i} R_{i, t}^{e}+\hat{c}_{6} D E F_{t}+$ $\hat{c}_{7} T E R M_{t}$, where $\hat{c}$ is the OLS estimate of $c$. As Vassalou (2003) points out, the coefficient

\footnotetext{
${ }^{8}$ http://www.hec.unil.ch/agoyal/.
} 
estimates are regarded as portfolio weights and do not need to sum up to one, since all variables on the right-hand side of (12) are zero-investment portfolios. We conduct our analysis at quarterly as well as monthly horizons. In case of monthly frequency, we first estimate the coefficients in (12) using quarterly data and then use these estimates as weights for the monthly analogue of $R_{i}^{e}, D E F$, and $T E R M$ to create $R_{G D P}$.

\section{Empirical results}

In this section we first begin by analysing the relationship between GDP growth and the seven assets used to construct the mimicking portfolio. In particular, we are interested to see how much of the variation of future GDP growth is captured by these assets. We then briefly summarize the cross-sectional asset pricing approach for the empirical analysis.

\subsection{A first glance at the factor mimicking portfolio}

Table 2 summarizes the results of the regression model defined in (12). In line with Vassalou (2003), we test only for the joint significance of the explanatory variables, since the presence of multicollinearity among the regressors will lead to an imprecise inference about the individual coefficient estimates.

[Table 2 around here]

The second column of Table 2 gives the results from predicting the GDP growth over the period 1971:Q1 to 2013:Q4 (full sample). Some 19.7\% of the variation in future GDP growth is captured by the model. The asymptotic $p$-value of the Wald test is lower than the conventional levels, indicating that the slope coefficients are jointly significant. The results suggest that the return of the five futures and two fixed income portfolios possesses forecasting power about next years GDP growth. We investigate in columns three and four the regression model performance in two non-overlapping subsamples. The break point of the full sample is chosen to highlight the rapid growth of commodity investments since early 2000s, which many researchers believe changed commodity futures price behaviour (see, e.g., Sockin and Xiong, 2014; Tang and Xiong, 2012). The adjusted $R$-squared for the first subsample that ends in 1999:Q4 is 31.9\% while that for the second is $23.1 \%$. The asymptotic $p$-value of the Wald test is lower than conventional levels for both subsamples. 


\subsection{Empirical methods}

A standard approach in the asset pricing literature is to normalize the mean of the SDF to one, i.e. $E[M]=1$, so that $(10)$ becomes:

$$
E\left[\boldsymbol{R}^{e}\right]=-\operatorname{cov}\left[\boldsymbol{R}^{e}, M\right]
$$

where $\boldsymbol{R}^{e}$ is a $5 \times 1$ vector of percentage net basis portfolio excess returns. For the ease of exposition we rewrite the SDF specification in (11) as:

$$
M_{t}=1-\left(f_{t}-\mu_{f}\right)^{\prime} b
$$

where $f_{t}$ is a $2 \times 1$ vector of risk factors whose first element is $R_{E W A, t}$ and the second element is $R_{G D P, t} \cdot \mu_{f}=E\left(f_{t}\right)$, and $b$ is a vector with the associated factor loadings. This specification implies a beta representation of the form:

$$
E\left[\boldsymbol{R}^{e}\right]=\underbrace{\operatorname{cov}\left(\boldsymbol{R}^{e}, f\right) \Sigma_{f}^{-1}}_{\boldsymbol{\beta}} \underbrace{\Sigma_{f} b}_{\boldsymbol{\lambda}},
$$

where $\Sigma_{f}=E\left[\left(f_{t}-\mu_{f}\right)\left(f_{t}-\mu_{f}\right)^{\prime}\right]$. Representation (15) states that the expected excess returns of the five percentage net basis portfolios depend on their exposure to the candidate risk factors, i.e. $\beta$, and the factor risk premium, $\boldsymbol{\lambda}$.

To estimate the parameters of (15) along with the mean of $f$ we use Hansen's (1982) Generalized Method of Moments (GMM). Following Burnside (2012) we focus on the moment condition:

$$
E\left\{\left[1-\left(f-\mu_{f}\right)^{\prime} b\right] R^{e}\right\}=0
$$

The GMM estimator of the factor means is $\mu_{f}=\bar{f}$ and of the factor loadings is

$$
\hat{b}=\left(d_{T}^{\prime} W_{T} d_{T}\right)^{-1} d_{T}^{\prime} W_{T} \overline{\boldsymbol{R}}^{e}
$$

where $d_{T}$ denotes the covariance of $\boldsymbol{R}^{e}$ with $f, W_{T}$ is the prespecified weighting matrix, and $\overline{\boldsymbol{R}}^{e}$ denotes the sample mean of $\boldsymbol{R}^{e}$. Let $\hat{\Sigma}_{f}$ be the sample covariance matrix of $f$ so that estimates of the factor prices are obtained as:

$$
\hat{\lambda}=\hat{\Sigma}_{f} \hat{b}
$$

We take $W_{T}$ to be the identity matrix. Burnside (2012) points out that in this case the (first stage) GMM estimates of $\boldsymbol{\lambda}$ are numerically identical to those of the cross-sectional (second- 
pass) regression of Fama and MacBeth (1973). Using the two factors $R_{E W A, t}$ and $R_{G D P, t}$ the cross-sectional regression is expressed as:

$$
\bar{R}_{i}^{e}=\hat{\beta}_{i, R_{E W A}} \lambda_{R_{E W A}}+\hat{\beta}_{i, R_{G D P}} \lambda_{R_{G D P}}+\hat{a}_{i}
$$

where the residuals $\hat{a}_{i}$ are pricing errors, whose GMM analogue is defined as:

$$
\hat{\boldsymbol{a}}=\overline{\boldsymbol{R}}^{e}-d_{T} \hat{b}
$$

The factor loadings $\hat{\beta}_{i}$ in (19) are the coefficients in the multiple regression:

$$
R_{i, t}^{e}=a_{i}+\beta_{i, R_{E W A}} R_{E W A, t}+\beta_{i, R_{G D P}} R_{G D P, t}+u_{i, t} .
$$

The betas are viewed as a measure of systematic risk of portfolio futures excess returns and $u_{i, t}$ captures the idiosyncratic component of the portfolios.

In the next section, we test the relevance of the model using the $J$-statistic, which is given by $T \hat{\boldsymbol{a}} V_{T}^{-1} \hat{\boldsymbol{a}}$, with $\hat{\boldsymbol{a}}$ defined in (20) and $V_{T}^{-1}$ is the generalized inverse of the (consistently estimated) asymptotic covariance matrix, $\sqrt{T} \hat{\boldsymbol{a}}$ (Burnside, 2012). Under the null hypothesis that all pricing errors are jointly zero, the statistic is asymptotically distributed as $\chi^{2}$ with three degrees of freedom.

\subsection{Asset pricing results}

Panel A of Table 3 shows the empirical results of the asset pricing test estimated by the GMM procedure.

[Table 3 around here]

The results based on quarterly data are qualitatively similar to those based on monthly data. The model captures the cross-sectional variation of returns quite well with $R$-squared statistics of around $90 \%$. We also observe a very high $p$-value of the $J$-statistic at both frequencies, suggesting that the null hypothesis of the pricing errors being jointly zero cannot be rejected. The GMM estimates of $b$ and $\lambda$ associated with the factor-mimicking portfolio are both negative and statistically significant, whereas those associated with the EWA portfolio are positive but only $\lambda_{R_{E W A}}$ is significant. The negative price of risk implies demand for a higher premium for portfolios whose returns have negative covariance with the GDP-related factor. By contrast, if portfolio returns comove positively with $R_{G D P}$, then the negative $\lambda_{R_{G D P}}$ will translate into a lower risk premium. 
The asset pricing results in Table 3 are interesting since Vassalou (2003) finds that news related to GDP growth is also a significant risk factor (along with the market portfolio) in the cross-section of equity returns. Therefore, the same risk factor drives returns in both the equity and commodity futures markets. As Campbell and Hamao (1992) point out, a finding of common risk characteristics is suggestive of market integration.

To investigate which futures portfolio provides a hedge against news about future GDP growth, Panel B in Table 3 summarizes the coefficient estimates from the time-series regressions in (21). We estimate the parameters jointly by GMM which delivers heteroscedasticity and autocorrelation (HAC) consistent standard errors. The results show that there is a high crosssectional dispersion in the betas associated with the GDP-related factor which is necessary for the model to be successful. They are all statistically significant and economically large at the monthly and quarterly frequencies, except for portfolios $P 3$ and $P 4$. Interestingly, these are the only two portfolios whose abnormal returns (i.e. $a_{3}$ and $a_{4}$ ) are insignificantly different from zero. The $R$-squareds are all reasonable and in the range between $43 \%$ and $62 \%$. The opposite sign of the factor loadings for the extreme portfolios, $P 1$ and $P 5$, suggests that if the return of the mimicking portfolio increases, the return of futures with low percentage net basis will increase and the return of futures with high percentage net basis will decrease. Excess returns on all five futures portfolios have significantly positive loadings with respect to the $R_{E W A}$ factor but all estimates are very close to one. Since in the cross-sectional regression these betas act like a constant, we can regard $\lambda_{R_{E W A}}$ as the models pricing error for the risk-free rate (see, Burnside, 2012).

In Figure 1 we present the fit of this model by plotting the sample average excess returns on the $x$-axis and the fitted average excess returns on the $y$-axis.

[Figure 1 around here]

Ideally, the data points should lie exactly on the 45-degree straight line but as we can see there are some pricing errors that are particularly large in the case of portfolio $P 4$ for quarterly data (Panel A) and $P 1$ for monthly data (Panel B). Nevertheless, the model appears to fit the data well, which corroborates the low cross-sectional mean absolute standard error (MAE) of $0.31 \%$ at quarterly frequency and $0.14 \%$ at monthly frequency (Table 3 ).

Overall, this section shows that news about future GDP growth, captured by a factor mimicking portfolio, helps in understanding the cross-section of commodity futures excess return. These findings are in line with Frankel (2014) who argues that expectations about future economic activity has a direct effect on transition demand for inventories and thus on spot and futures contract prices. 


\subsection{A horse race with HML}

In this section we compare the performance of our two factor model with a model whose SDF specification includes $R_{E W A}$ and the return on the HML portfolio $\left(R_{H M L}\right)$ described in Section 3. The unconditional correlation between HML and the GDP-related factor is $-41 \%$, suggesting that $R_{G D P}$ contains some additional information that is not captured by the HML. This prompts consideration of the case where $R_{E W A}, R_{G D P}$, and $R_{H M L}$ are included jointly in the SDF.

The SDF parameter estimates and the time-series regression coefficients for the first case are shown in Table 4, Panels A-B. Consistent with the analysis in Table 3, the results for quarterly (left panel) as well as monthly (right panel) frequency are reported.

[Table 4 around here]

The use of quarterly data produces qualitatively similar results to those using monthly data. The model which includes $R_{E W A}$ and $R_{H M L}$ has a high cross-sectional $R$-squared statistic of $84 \%(86 \%)$ for quarterly (monthly) data. The $b$ and $\lambda$ associated with the HML factor are positive and statistically significant. However, the model using quarterly data is rejected since the $J$-statistic of all pricing errors being jointly zero is insignificant at the $5 \%$ level. By contrast, the model using monthly data is rejected at the $10 \%$ but not at $5 \%$ significance level. The results from the time series regressions in Panel $\mathrm{B}$ reveal that the $R_{H M L}$ betas are very close to -0.5 and 0.5 for $P 1$ and $P 5$, respectively, and very close to zero for the other three portfolios. This pattern is consistent with the way HML has been created and, as Burnside (2012) points out, the failure of these types of models is due to their poor performance in explaining the returns of non-extreme portfolios.

The SDF and time-series estimates for the second case, where we include both the factormimicking portfolio for news about future GDP growth and HML, are reported in Table 5.

[Table 5 around here]

The estimate of the SDF factor loading in Panel A associated with the HML portfolio is no longer significant, even though $\lambda_{R_{H M L}}$ is statistically significant. The $b$ parameter associated with $R_{G D P}$ is also lower than the one reported in Table 3 but still statistically significant at the $10 \%$ level. The model is successful in explaining the cross-section of portfolio returns since the hypothesis of all pricing errors being jointly zero cannot be rejected at conventional levels, with a $J$-statistic of 1.553 at the quarterly frequency (left panel) and 1.051 at the monthly frequency (right panel). The factor betas in Panel B associated with the GDP portfolio are somewhat lower than that reported in Table 3 but the conclusions remain qualitatively similar.

In Table 6 we report results from analysis similar to those in Table 5 but now the HML portfolio is orthogonalized with respect to the GDP mimicking portfolio. 
[Table 6 around here]

The results show that, following the orthogonalization, $R_{H M L}$ is no longer priced in the crosssection of commodity futures returns, i.e. $\lambda_{R_{H M L}}$ is no longer significant at even $10 \%$ level. By contrast, news related to future GDP growth is a highly significant risk factor with corresponding (GMM) $t$-statistics of -2.456 and -2.596 for $b$ and $\lambda$, respectively. It seems reasonable to conclude from these results that $R_{G D P}$ contains additional information that is not captured by the return of the HML portfolio. ${ }^{9}$

\section{Alternative futures sorted portfolios}

The performance of the factor-mimicking portfolio is impressive. However, it is interesting to verify whether the pricing power of this factor is affected by the choice of underlying test assets. In this section we investigate the ability of the two $R_{E W A}$ and $R_{G D P}$ factors in explaining the cross-section of commodity futures portfolios sorted on either the basis or momentum.

We follow the strategy outlined in Section 3 in sorting commodity futures excess returns into portfolios, but we sort on the basis and momentum instead of the percentage net basis. Following Gorton, Hayashi, and Rouwenhorst (2013), we define the basis as:

$$
\left(\frac{F_{t}^{(1)}}{F_{t}^{(2)}}-1\right) \times \frac{365}{\tau_{2}-\tau_{1}} .
$$

Again $\tau_{1}$ is the number of days to the expiration of the nearest contract, $F_{t}^{(1)}$, and $\tau_{2}$ is the number of days to the expiration of the next-to-nearest contract, $F_{t}^{(2)}$. Table 7 summarizes the descriptive statistics for these five portfolios at monthly and quarterly frequency.

[Table 7 around here]

The monotonic pattern of (annualized) average returns is consistent with the results in Yang (2013) and Szymanowska, de Roon, Nijman, and van den Goorbergh (2014). The return of HML portfolio based on the basis is slightly higher than the corresponding portfolio based on percentage net basis. Indeed, the two variables are almost identical but the percentage net basis is adjusted for the interest rate between time $t$ and $t+1$. In the last row of Panel $\mathrm{A}$ we report the correlation between the returns of these two sorting strategies. It is evident that the two variables capture the same information, since the correlation coefficients are in the vicinity of unity. The conclusions at the monthly frequency are identical.

\footnotetext{
${ }^{9}$ Interestingly, Vassalou (2003) arrives at a similar conclusion for the two Fama-French factors. The two factors are the return of a portfolio strategy that buys stocks with high book-to-market ratio and sells stocks with low book-to-market, and the return of a portfolio strategy that buys small stocks and sells big stocks ((see, e.g. Fama and French, 1993).
} 
Table 8 summarizes the return characteristics of momentum portfolios. Consistent with Miffre and Rallis (2007), we measure momentum as the average futures excess returns over the prior 12 months.

[Table 8 around here]

Unlike the results in Table 1 and 7, the annual average excess returns on momentum-based portfolios are not monotonically increasing, regardless of the data frequency. Nevertheless, the strategy that combines a long position in portfolio $P 5$ with a short position in portfolio $P 1$ is highly profitable, with an annual average excess return that is comparable with the long-short portfolios based on ether the basis or percentage net basis. The monthly momentum based portfolio returns are highly positively skewed and the skewness lessens as we move from $P 1$ to $P 5$. At the quarterly frequency this pattern is reversed - portfolios $P 1$ through $P 3$ have relatively small positive skewness, whereas for $P 4$ and $P 5$ it is around one. In contrast, the conditional distribution of returns from the HML strategy is quite symmetric and with excess kurtosis of 0.73 . This suggests that the momentum based long-short portfolio is characterised by lower crash risk than the one based on the basis or the percentage net basis. The asset pricing results for the basis portfolios are shown in Panel A of Table 9. To conserve space we report estimates only from the SDF approach. ${ }^{10}$

[Table 9 around here]

At the quarterly frequency (left panel) our two factor model is successful at the $5 \%$ level of significance in explaining the cross-section of portfolio excess returns sorted on the basis but fails at the $10 \%$ level, since the $p$-value of the $J$-statistic is 0.09 . However, at monthly frequency (right panel) the pricing errors of the basis portfolios are statistically insignificant at even the $10 \%$ level. The cross-sectional $R$-squared statistics are around $80 \%$ and the estimates of the SDF parameters are similar to the benchmark specification in Table 3.

Figure 2 shows the fit of the model for the basis portfolios. We observe a similar pattern to the plot in Figure 1. In particular, there are some pricing errors for portfolios $P 1$ and $P 4$ at both quarterly (Panel A) and monthly (Panel B) frequency. Nevertheless, the MAE statistics is below $1 \%$ suggesting that overall the cross-sectional pricing error is not that large.

[Figure 2 around here]

Panel B of Table 9 shows the results for the momentum based portfolios. The model explains the cross-section of portfolio returns quite well. The pricing errors are statistically insignificant at conventional levels. The monthly frequency $R$-squared is $97 \%$ and the MAE is $0.07 \%$. The good fit of the model is also evident from the plot in Figure 3, where all momentum portfolios line up

\footnotetext{
${ }^{10}$ The results from the time series analysis offer qualitatively similar conclusions to those in Table 3. These results are available from the authors upon request.
} 
close to the diagonal line at both the quarterly (Panel A) and monthly (Panel B) frequencies.

[Figure 3 around here]

The negative exposure of these portfolios to the GDP-related factor is higher than the exposure of portfolios based on basis or percentage net basis. $\lambda_{R_{G D P}}$ is also negative and significant. The EWA portfolio results are similar to those in Panel A of Table 3.

To sum up, we find that news related to GDP growth is a priced risk factor in the crosssection of commodity futures returns and these findings are robust with the choice of underlying test assets.

\section{Conclusion}

This paper employs a sample of 26 commodity futures over the period from December 1969 to December 2012 to investigate the role of news about future GDP growth as a risk factor in the pricing of the cross section of commodity futures returns. This is motivated by the notion that expectations about future growth prospects are informative about inventories. The paper employs a cross-sectional asset pricing framework under the assumption that there is a parsimonious two factor pricing kernel that covaries significantly with returns. The first factor is a simple average of the set of all futures contracts and the second is a mimicking portfolio that captures news related to future GDP growth.

The results show that the percentage net basis (net convenience yield to price ratio) is informative about future yield growth and future risk premium. Sorting commodity futures into portfolios based on the percentage net basis results in monotonically increasing average excess returns. We argue that these portfolio returns are a compensation for risk associated with news about future GDP growth. We find that commodity futures with low percentage net basis provide a hedge against risk associated with future GDP growth, whereas futures with high percentage net basis comove negatively with the factor. The cross-sectional fit of the asset pricing model is impressive since it accounts for more than $90 \%$ of the spread in the sorted portfolios. Our empirical results support risk-based explanations for abnormal commodity futures returns. Since Vassalou (2003) found news about future GDP growth can explain the cross section of equity returns our findings provide indirect evidence on the integration of equity and commodity markets.

Our findings have some important practical implications but also provide several opportunities for further research. In terms of practical implications, we suggest that both investors and policy makers could use the news related to the GDP growth factor when modelling and forecasting commodity returns. Investors should certainly consider this factor when forming 
portfolios as otherwise, ceteris paribus, they may assume more risk than desired by investor characteristics. Relatedly, investors could consider using commodity futures with a low percentage net basis to provide a hedge against future GDP growth risk. Finally, in terms of further work, one might usefully consider the impact of regulation, business cycles or even natural disasters and climate change on commodity futures returns and risk. We leave these to future research.

\section{Appendix A}

In this appendix we provide details of the percentage net basis approximation in Section 2. The derivations are reproduced from Pindyck (1993).

Similar to Campbell and Shiller (1988), we relate the percentage net basis to the ex ante yield growth and excess return forecasts by approximating the one period return identity:

$$
h_{t+1}=\frac{S_{t+1}+C_{t+1}}{S_{t}}-1 \text {. }
$$

Given that $z_{t} \equiv C_{t} / S_{t}$, we can rewrite the return as a function of the percentage net basis and the convenience yield:

$$
h_{t+1}=\frac{C_{t+1} z_{t}}{z_{t+1} C_{t}}+\frac{C_{t+1} z_{t}}{C_{t}}-1 .
$$

Linearizing around the means $\bar{z}$ and $\bar{C}$ yields:

$$
\begin{aligned}
h_{t+1} \approx \bar{z} & +\left(\frac{1}{\bar{C}}+\frac{\bar{z}}{\bar{C}}\right)\left(C_{t+1}-\bar{C}\right)-\left(\frac{1}{\bar{C}}+\frac{\bar{z}}{\bar{C}}\right)\left(C_{t}-\bar{C}\right) \\
& +\left(1+\frac{1}{\bar{z}}\right)\left(z_{t}-\bar{z}\right)-\frac{1}{\bar{z}}\left(z_{t+1}-\bar{z}\right) .
\end{aligned}
$$

Simplifying (A3), letting $\rho=(1+\bar{z})^{-1}$, and defining the normalized variables $z_{t}^{\prime}=z_{t} / \bar{z}$ and $C_{t}^{\prime}=C_{t} / \bar{C}$, gives:

$$
\rho h_{t+1} \approx z_{t}^{\prime}-\rho z_{t+1}^{\prime}+\Delta C_{t+1}^{\prime}
$$

As in Campbell and Shiller (1988), we can iterate forward and impose the terminal condition $\lim _{j \rightarrow \infty} \rho^{j} z_{t+j}=0$ to obtain the approximate identity:

$$
z_{t}^{\prime} \approx \sum_{j=0}^{\infty} \rho^{j}\left(\rho h_{t+j+1}-\Delta C_{t+j+1}^{\prime}\right) .
$$

Since (A5) holds ex post it should also hold ex ante. Taking conditional expectations, we obtain $(6)$. 


\section{References}

Bessembinder, Hendrik, 1992, Systematic risk, hedging pressure, and risk premiums in futures markets, Review of Financial Studies 5, 637-667.

- and Kalok Chan, 1992, Time-varying risk premia and forecastable returns in futures markets, Journal of Financial Economics 32, 169-193.

Brennan, Michael J, 1958, The supply of storage, American Economic Review 48, 50-72.

Burnside, Craig, 2012, Carry trades and risk, in Jessica James, Ian W Marsh, and Lucio Sarno, ed.: Handbook of exchange rates (John Wiley \& Sons, Inc., Hoboken).

Campbell, John Y, and Yasushi Hamao, 1992, Predictable stock returns in the united states and japan: A study of long-term capital market integration, Journal of Finance 47, 43-69.

Campbell, John Y, and Robert J Shiller, 1988, Stock prices, earnings, and expected dividends, Journal of Finance 43, 661-676.

Chan, Kalok, 1992, A further analysis of the lead-lag relationship between the cash market and stock index futures market, Review of financial studies 5, 123-152.

Cochrane, John H, 2005, Asset pricing (Princeton University Press, Princeton).

Daskalaki, Charoula, Alexandros Kostakis, and George Skiadopoulos, 2014, Are there common factors in individual commodity futures returns?, Journal of Banking $\&$ Finance 40, 346-363.

Dusak, Katherine, 1973, Futures trading and investor returns: An investigation of commodity market risk premiums, Journal of Political Economy 81, 1387-1406.

Erb, Claude B, and Campbell R Harvey, 2006, The strategic and tactical value of commodity futures, Financial Analysts Journal 62, 69-97.

Ergün, Tolga A, 2009, Nyse rule 80a restrictions on index arbitrage and market linkage, Applied Financial Economics 19, 1675-1685.

Fama, Eugene F, and Kenneth R French, 1987, Commodity futures prices: Some evidence on forecast power, premiums, and the theory of storage, Journal of Business 60, 55-73.

— 1993, Common risk factors in the returns on stocks and bonds, Journal of Financial Economics 33, 3-56. 
Fama, Eugene F, and James D MacBeth, 1973, Risk, return, and equilibrium: Empirical tests, Journal of Political Economy 81, 607-636.

Fernandez-Perez, Adrian, Ana-Maria Fuertes, and Joëlle Miffre, 2015, Commodity markets, long-run predictability and intertemporal pricing, Review of Finance, Forthcoming.

Fleming, Jeff, Barbara Ostdiek, and Robert E Whaley, 1996, Trading costs and the relative rates of price discovery in stock, futures, and option markets, Journal of Futures Markets 16, $353-387$.

Frankel, Jeffrey A, 2014, Effects of speculation and interest rates in a carry trade model of commodity prices, Journal of International Money and Finance 42, 88-112.

Gorton, Gary, and Geert K Rouwenhorst, 2006, Facts and fantasies about commodity futures, Financial Analysts Journal 62, 47-68.

Gorton, Gary B, Fumio Hayashi, and Geert K Rouwenhorst, 2013, The fundamentals of commodity futures returns, Review of Finance 17, 35-105.

Hansen, Lars P, 1982, Large sample properties of generalized method of moments estimators, Econometrica 50, 1029-1054.

Hicks, John R, 1939, Value and capital (Oxford University Press).

Jagannathan, Ravi, 1985, An investigation of commodity futures prices using the consumptionbased intertemporal capital asset pricing model, Journal of Finance 40, 175-191.

Kaldor, Nicholas, 1939, Speculation and economic stability, Review of Economic Studies 7, $1-27$.

Keynes, John M, 1930, A treatise on money . vol. II (McMillan, London).

Lustig, Hanno, and Adrien Verdelhan, 2007, The cross section of foreign currency risk premia and consumption growth risk, American Economic Review 97, 89-117.

Menkhoff, Lukas, Lucio Sarno, Maik Schmeling, and Andreas Schrimpf, 2012, Carry trades and global foreign exchange volatility, Journal of Finance 67, 681-718.

Merton, Robert C, 1973, An intertemporal capital asset pricing model, Econometrica 41, 867887.

Miffre, Joëlle, and Georgios Rallis, 2007, Momentum strategies in commodity futures markets, Journal of Banking $\mathcal{G}$ Finance 31, 1863-1886. 
Newey, Whitney K, and Kenneth D West, 1987, A simple, positive semi-definite, heteroskedasticity and autocorrelation consistent covariance matrix, Econometrica 55, 703-708.

Ng, Victor K, and Craig Pirrong, 1994, Fundamentals and volatility: Storage, spreads, and the dynamics of metals prices, Journal of Business 67, 203-230.

Pindyck, Robert S, 1993, The present value model of rational commodity pricing, Economic Journal 103, 511-530.

— , 2001, The dynamics of commodity spot and futures markets: a primer, Energy Journal $22,1-29$.

— 2004, Volatility and commodity price dynamics, Journal of Futures Markets 24, 10291047.

Sockin, Michael, and Wei Xiong, 2014, Informational frictions and commodity markets, Journal of Finance Forthcoming.

Szymanowska, Marta, Frans de Roon, Theo Nijman, and Rob van den Goorbergh, 2014, An anatomy of commodity futures risk premia, Journal of Finance 69, 453-482.

Tang, Ke, and Wei Xiong, 2012, Index investment and the financialization of commodities, Financial Analysts Journal 68.

Vassalou, Maria, 2003, News related to future gdp growth as a risk factor in equity returns, Journal of Financial Economics 68, 47-73.

Working, Holbrook, 1949, The theory of price of storage, American Economic Review 39, 12541262.

Yang, Fan, 2013, Investment shocks and the commodity basis spread, Journal of Financial Economics 110, 164-184. 


\section{Table 1}

\section{Descriptive statistics}

The table presents excess return characteristics of portfolios sorted on the percentage net basis at two frequencies: monthly (Panel A) and quarterly (Panel B). The portfolios are constructed so that $P 1$ contains the quintile of futures returns with the lowest percentage net basis, whereas $P 5$ contains the quintile of futures with the highest percentage net basis. The percentage net basis is defined as the ratio between the convenience yield and the spot price. The reported mean, median, and standard deviation are annualized and in per cent. Kurtosis represents the sample excess kurtosis relative to the normal distribution. SR represents the Sharpe ratio. EWA denotes the equally-weighted average return on a long position in all five portfolios. HML is the return difference between $P 5$ and $P$ 1, i.e. it represents the return from buying portfolio 5 and shorting portfolio 1 . The sample runs from December 1969 to December 2012.

\begin{tabular}{lrrrrrrr}
\hline Statistic & $P 1$ & $P 2$ & $P 3$ & $P 4$ & $P 5$ & EWA & HML \\
\hline \multicolumn{7}{c}{ Panel A: Monthly returns } \\
\hline Mean & -2.792 & -0.151 & 5.326 & 7.472 & 14.794 & 4.930 & 17.586 \\
Median & -3.754 & -3.395 & 5.777 & 5.369 & 9.083 & 6.452 & 15.325 \\
Std. & 19.926 & 17.463 & 17.925 & 18.988 & 20.659 & 13.564 & 23.015 \\
Skewness & 0.922 & 0.632 & -0.117 & 0.247 & 0.764 & 0.178 & -0.241 \\
Kurtosis & 4.728 & 2.404 & 1.594 & 2.927 & 3.229 & 3.323 & 1.689 \\
SR & -0.140 & -0.009 & 0.297 & 0.394 & 0.716 & 0.363 & 0.764 \\
\hline \multicolumn{7}{c}{ Panel B: Quarterly returns } \\
\hline Mean & -2.742 & -0.184 & 5.461 & 7.476 & 15.346 & 5.071 & 18.088 \\
Median & -5.032 & -1.182 & 4.042 & 10.538 & 11.76 & 6.411 & 21.145 \\
Std. & 20.079 & 17.215 & 18.571 & 19.005 & 23.108 & 13.844 & 26.574 \\
Skewness & 0.752 & 0.308 & -0.163 & 0.220 & 0.721 & -0.148 & -0.103 \\
Kurtosis & 3.404 & 0.445 & 0.977 & 0.958 & 1.653 & 1.556 & 1.861 \\
SR & -0.137 & -0.011 & 0.294 & 0.393 & 0.664 & 0.366 & 0.681 \\
\hline
\end{tabular}




\section{Table 2}

\section{Descriptive statistics}

The table summarizes the results from the predictive regression:

$$
G D P G_{t+4}=c_{0}+\sum_{i=1}^{5} c_{i} R_{i, t}^{e}+c_{6} D E F_{t}+c_{7} T E R M_{t}+\epsilon_{t+4},
$$

where $R_{i, t}^{e}$ is the return on the percentage net basis portfolio $i$ at time $t$ (see notes to Table 1 ), DEF is the difference between the return of a long-term corporate and long-term government bonds, and TERM is the difference between the yields of long-term government bonds and the 3-month Treasury bill. GDPG is the seasonally adjusted real GDP growth over the period 1971:Q1 to 2013:Q4. Numbers in parentheses are Newey and West (1987) heteroscedasticity and autocorrelation consistent standard errors. $\chi^{2}$ is the asymptotic $p$-value of the Wald test of all slope coefficients in the regression being jointly zero. The results are reported for the full sample as well as two non-overlapping sub-periods.

\begin{tabular}{lrrr}
\hline & 1971Q1:2013Q4 & 1971Q1:1999Q4 & 2000Q1:2013Q4 \\
\hline Con. & 0.019 & 0.019 & 0.009 \\
$P 1$ & $(0.005)$ & $(0.005)$ & $(0.005)$ \\
& 0.022 & 0.000 & 0.074 \\
$P 2$ & $(0.024)$ & $(0.021)$ & $(0.045)$ \\
& 0.024 & 0.023 & -0.014 \\
$P 3$ & $(0.021)$ & $(0.021)$ & $(0.032)$ \\
& -0.019 & -0.006 & -0.026 \\
$P 4$ & $(0.021)$ & $(0.022)$ & $(0.032)$ \\
& -0.018 & -0.011 & -0.038 \\
$P 5$ & $(0.018)$ & $(0.016)$ & $(0.032)$ \\
& -0.038 & -0.035 & -0.021 \\
DEF & $(0.016)$ & $(0.016)$ & $(0.031)$ \\
& 0.125 & 0.059 & 0.179 \\
TERM & $(0.094)$ & $(0.076)$ & $(0.107)$ \\
& 0.554 & 0.817 & -0.171 \\
Adj.R ${ }^{2}$ & $(0.156)$ & $(0.187)$ & $(0.171)$ \\
$\chi^{2}$ & 0.197 & 0.316 & 0.231 \\
\hline
\end{tabular}


Table 3

\section{Asset pricing results for the GDP-related factor}

The table reports the cross-sectional asset pricing results (Panel A) and the time series-estimates (Panel B) of a two factor model, where the first factor is the average return from all percentage net basis portfolios (denoted as $R_{E W A}$ ) and the second factor is the return on a mimicking portfolio that captures news related to future GDP growth (denoted as $R_{G D P}$ ). In both panels the parameters are estimated via GMM, with heteroscedasticity and autocorrelation consistent standard errors in parentheses. All estimates are reported in per cent. The $J$-statistic for the overidentifying restrictions is also reported, with the corresponding $p$-value in parentheses. MAE represents the cross-sectional mean absolute standard error.

\begin{tabular}{|c|c|c|c|c|c|c|c|c|c|c|c|}
\hline \multicolumn{12}{|c|}{ Panel A: Factor Prices } \\
\hline \multicolumn{6}{|c|}{ Quarterly } & \multicolumn{6}{|c|}{ Monthly } \\
\hline GMM & $R_{E W A}$ & $R_{G D P}$ & $R^{2}$ & $J$ & MAE & GMM & $R_{E W A}$ & $R_{G D P}$ & $R^{2}$ & $J$ & MAE \\
\hline \multirow[t]{2}{*}{$b$} & 1.060 & -70.010 & 0.924 & 1.536 & 0.312 & $b$ & 1.443 & -86.575 & 0.891 & 1.845 & 0.139 \\
\hline & $(1.572)$ & $(20.132)$ & & $(0.674)$ & & & $(1.511)$ & $(20.596)$ & & $(0.605)$ & \\
\hline \multirow[t]{2}{*}{$\lambda$} & 1.263 & -0.812 & & & & $\lambda$ & 0.407 & -0.717 & & & \\
\hline & $(0.527)$ & $(0.214)$ & & & & & $(0.172)$ & $(0.166)$ & & & \\
\hline \multicolumn{12}{|c|}{ Panel B: Factor Betas } \\
\hline \multicolumn{6}{|c|}{ Quarterly } & \multicolumn{6}{|c|}{ Monthly } \\
\hline Portfolios & Con. (\%) & $R_{E W A}$ & $R_{G D P}$ & $R^{2}$ & & Portfolios & Con. (\%) & $R_{E W A}$ & $R_{G D P}$ & $R^{2}$ & \\
\hline \multirow[t]{2}{*}{$P 1$} & -3.424 & 0.961 & 1.701 & 0.436 & & $P 1$ & -1.180 & 1.020 & 0.505 & 0.482 & \\
\hline & $(0.711)$ & $(0.113)$ & $(0.668)$ & & & & $(0.272)$ & $(0.062)$ & $(0.218)$ & & \\
\hline \multirow[t]{2}{*}{$P 2$} & -2.596 & 0.942 & 1.517 & 0.567 & & $P 2$ & -1.173 & 0.961 & 0.731 & 0.562 & \\
\hline & $(0.619)$ & $(0.065)$ & $(0.483)$ & & & & $(0.240)$ & $(0.047)$ & $(0.175)$ & & \\
\hline \multirow[t]{2}{*}{$P 3$} & 0.285 & 0.981 & -0.183 & 0.540 & & $P 3$ & 0.074 & 0.969 & -0.027 & 0.538 & \\
\hline & $(0.670)$ & $(0.063)$ & $(0.501)$ & & & & $(0.280)$ & $(0.052)$ & $(0.202)$ & & \\
\hline \multirow[t]{2}{*}{$P 4$} & 0.445 & 0.982 & 0.200 & 0.507 & & $P 4$ & 0.247 & 0.978 & -0.025 & 0.489 & \\
\hline & $(0.743)$ & $(0.077)$ & $(0.601)$ & & & & $(0.276)$ & $(0.060)$ & $(0.197)$ & & \\
\hline \multirow[t]{2}{*}{$P 5$} & 5.289 & 1.135 & -3.235 & 0.612 & & $P 5$ & 2.032 & 1.071 & -1.184 & 0.543 & \\
\hline & $(0.976)$ & $(0.079)$ & $(0.783)$ & & & & $(0.318)$ & $(0.057)$ & $(0.230)$ & & \\
\hline
\end{tabular}


Table 4

\section{Asset pricing results for the HML portfolio}

The table reports the cross-sectional asset pricing results (Panel A) and the time series-estimates (Panel B) of a two factor model, where the first factor is the average return from all percentage net basis portfolios (denoted as $R_{E W A}$ ) and the second factor is the return on a portfolio long in $P 5$ and short in $P 1$ (denoted as $R_{H} M L$ ). See also notes to Table 3.

\begin{tabular}{|c|c|c|c|c|c|c|c|c|c|c|c|}
\hline \multicolumn{12}{|c|}{ Panel A: Factor Prices } \\
\hline \multicolumn{6}{|c|}{ Quarterly } & \multicolumn{6}{|c|}{ Monthly } \\
\hline GMM & $R_{E W A}$ & $R_{H M L}$ & $R^{2}$ & $J$ & MAE & GMM & $R_{E W A}$ & $R_{H M L}$ & $R^{2}$ & $J$ & MAE \\
\hline \multirow[t]{2}{*}{$b$} & 2.033 & 2.386 & 0.836 & 7.959 & 0.487 & $b$ & 2.462 & 3.301 & 0.861 & 6.528 & 0.149 \\
\hline & $(1.267)$ & $(0.712)$ & & $(0.047)$ & & & $(1.161)$ & $(0.747)$ & & $(0.089)$ & \\
\hline \multirow[t]{2}{*}{$\lambda$} & 1.294 & 4.465 & & & & $\lambda$ & 0.415 & 1.483 & & & \\
\hline & $(0.527)$ & $(1.028)$ & & & & & $(0.172)$ & $(0.295)$ & & & \\
\hline \multicolumn{12}{|c|}{ Panel B: Factor Betas } \\
\hline \multicolumn{6}{|c|}{ Quarterly } & \multicolumn{6}{|c|}{ Monthly } \\
\hline Portfolios & Con. $(\%)$ & $R_{E W A}$ & $R_{H M L}$ & $R^{2}$ & & Portfolios & Con. (\%) & $R_{E W A}$ & $R_{H M L}$ & $R^{2}$ & \\
\hline \multirow[t]{2}{*}{$P 1$} & 0.184 & 1.062 & -0.490 & 0.815 & & $P 1$ & 0.067 & 1.051 & -0.499 & 0.808 & \\
\hline & $(0.343)$ & $(0.052)$ & $(0.037)$ & & & & $(0.116)$ & $(0.038)$ & $(0.025)$ & & \\
\hline \multirow[t]{2}{*}{$P 2$} & -1.260 & 0.903 & 0.015 & 0.533 & & $P 2$ & -0.379 & 0.952 & -0.017 & 0.546 & \\
\hline & $(0.436)$ & $(0.062)$ & $(0.044)$ & & & & $(0.150)$ & $(0.048)$ & $(0.025)$ & & \\
\hline \multirow[t]{2}{*}{$P 3$} & 0.425 & 1.006 & -0.074 & 0.550 & & $P 3$ & 0.119 & 0.973 & -0.051 & 0.542 & \\
\hline & $(0.537)$ & $(0.063)$ & $(0.042)$ & & & & $(0.162)$ & $(0.052)$ & $(0.026)$ & & \\
\hline \multirow[t]{2}{*}{$P 4$} & 0.467 & 0.966 & 0.039 & 0.510 & & $P 4$ & 0.126 & 0.974 & 0.066 & 0.495 & \\
\hline & $(0.567)$ & $(0.078)$ & $(0.061)$ & & & & $(0.180)$ & $(0.060)$ & $(0.037)$ & & \\
\hline \multirow[t]{2}{*}{$P 5$} & 0.184 & 1.062 & 0.510 & 0.861 & & $P 5$ & 0.067 & 1.051 & 0.501 & 0.821 & \\
\hline & $(0.343)$ & $(0.052)$ & $(0.037)$ & & & & $(0.116)$ & $(0.038)$ & $(0.025)$ & & \\
\hline
\end{tabular}


Table 5

\section{Asset pricing results for the HML and the GDP mimicking portfolios}

The table gives the cross-sectional asset pricing results (Panel A) and time series estimates (Panel B) of a three factor model. The first factor is the average return from all percentage net basis portfolios (denoted as $R_{E W A}$ ), the second factor is the return on a mimicking portfolio that captures news related to future GDP growth (denoted as $R_{G D P}$ ), and the third factor is the return on a portfolio long in P5 and short in P1 (denoted as $R_{H M L}$ ). See also notes to Table 3.

\begin{tabular}{|c|c|c|c|c|c|c|c|c|c|c|c|c|c|}
\hline \multicolumn{14}{|c|}{ Panel A: Factor Prices } \\
\hline \multicolumn{7}{|c|}{ Quarterly } & \multicolumn{7}{|c|}{ Monthly } \\
\hline GMM & $R_{E W A}$ & $R_{G D P}$ & $R_{H M L}$ & $R^{2}$ & $J$ & MAE & GMM & $R_{E W A}$ & $R_{G D P}$ & $R_{H M L}$ & $R^{2}$ & $J$ & MAE \\
\hline \multirow[t]{2}{*}{$b$} & 1.259 & -51.569 & 0.775 & 0.943 & 1.553 & 0.320 & $b$ & 1.823 & -51.508 & 1.675 & 0.962 & 1.051 & 0.093 \\
\hline & $(1.422)$ & $(27.703)$ & $(1.328)$ & & $(0.460)$ & & & $(1.291)$ & $(27.961)$ & $(1.296)$ & & $(0.591)$ & \\
\hline \multirow[t]{2}{*}{$\lambda$} & 1.264 & -0.649 & 4.540 & & & & $\lambda$ & 1.264 & -0.452 & 1.482 & & & \\
\hline & $(0.527)$ & $(0.250)$ & $(1.020)$ & & & & & $(0.527)$ & $(0.216)$ & $(0.296)$ & & & \\
\hline \multicolumn{14}{|c|}{ Panel B: Factor Betas } \\
\hline \multicolumn{7}{|c|}{ Quarterly } & \multicolumn{7}{|c|}{ Monthly } \\
\hline Portfolios & Con. (\%) & $R_{E W A}$ & $R_{G D P}$ & $R_{H M L}$ & $R^{2}$ & & Portfolios & Con. (\%) & $R_{E W A}$ & $R_{G D P}$ & $R_{H M L}$ & $R^{2}$ & \\
\hline \multirow[t]{2}{*}{$P 1$} & 1.085 & 1.051 & -0.853 & -0.518 & 0.822 & & $P 1$ & 0.460 & 1.046 & -0.357 & -0.510 & 0.811 & \\
\hline & $(0.633)$ & $(0.051)$ & $(0.438)$ & $(0.037)$ & & & & $(0.204)$ & $(0.037)$ & $(0.143)$ & $(0.025)$ & & \\
\hline \multirow[t]{2}{*}{$P 2$} & -3.259 & 0.928 & 1.893 & 0.076 & 0.578 & & $P 2$ & -1.195 & 0.960 & 0.743 & 0.007 & 0.562 & \\
\hline & $(0.654)$ & $(0.061)$ & $(0.469)$ & $(0.039)$ & & & & $(0.258)$ & $(0.047)$ & $(0.182)$ & $(0.026)$ & & \\
\hline \multirow[t]{2}{*}{$P 3$} & 1.116 & 0.998 & -0.654 & -0.095 & 0.555 & & $P 3$ & 0.250 & 0.972 & -0.119 & -0.055 & 0.543 & \\
\hline & $(0.815)$ & $(0.062)$ & $(0.534)$ & $(0.044)$ & & & & $(0.306)$ & $(0.052)$ & $(0.211)$ & $(0.027)$ & & \\
\hline \multirow[t]{2}{*}{$P 4$} & -0.027 & 0.972 & 0.468 & 0.054 & 0.512 & & $P 4$ & 0.026 & 0.975 & 0.091 & 0.069 & 0.495 & \\
\hline & $(0.812)$ & $(0.076)$ & $(0.561)$ & $(0.059)$ & & & & $(0.300)$ & $(0.060)$ & $(0.198)$ & $(0.038)$ & & \\
\hline \multirow[t]{2}{*}{$P 5$} & 1.085 & 1.051 & -0.853 & 0.482 & 0.866 & & $P 5$ & 0.460 & 1.046 & -0.357 & 0.490 & 0.824 & \\
\hline & $(0.633)$ & $(0.051)$ & $(0.438)$ & $(0.037)$ & & & & $(0.204)$ & $(0.037)$ & $(0.143)$ & $(0.025)$ & & \\
\hline
\end{tabular}


Table 6

\section{Asset pricing results for the HML and the GDP mimicking portfolios}

The setup in this table is the same as in Table 5 but HML is orthogonalized with respect to the factor-mimicking portfolio. In both panels the parameters are estimated via GMM, with heteroscedasticity and autocorrelation consistent standard errors in parentheses. The $J$-statistic for the overidentifying restrictions is reported, with the corresponding $p$-value in parentheses. MAE represents the cross-sectional mean absolute standard error.

\begin{tabular}{|c|c|c|c|c|c|c|c|c|c|c|c|c|c|}
\hline \multicolumn{14}{|c|}{ Panel A: Factor Prices } \\
\hline \multicolumn{7}{|c|}{ Quarterly } & \multicolumn{7}{|c|}{ Monthly } \\
\hline GMM & $R_{E W A}$ & $R_{G D P}$ & $R_{H M L}$ & $R^{2}$ & $J$ & MAE & GMM & $R_{E W A}$ & $R_{G D P}$ & $R_{H M L}$ & $R^{2}$ & $J$ & MAE \\
\hline \multirow[t]{2}{*}{$b$} & 1.823 & -55.523 & 0.775 & 0.943 & 1.553 & 0.320 & $b$ & 1.823 & -54.359 & 1.675 & 0.962 & 1.051 & 0.093 \\
\hline & $(1.422)$ & $(22.611)$ & $(1.328)$ & & $(0.460)$ & & & $(1.291)$ & $(26.263)$ & $(1.296)$ & & $(0.591)$ & \\
\hline \multirow[t]{2}{*}{$\lambda$} & 1.264 & -0.649 & 1.233 & & & & $\lambda$ & 0.409 & -0.452 & 0.712 & & & \\
\hline & $(0.527)$ & $(0.250)$ & $(1.721)$ & & & & & $(0.172)$ & $(0.216)$ & $(0.489)$ & & & \\
\hline \multicolumn{14}{|c|}{ Panel B: Factor Betas } \\
\hline \multicolumn{7}{|c|}{ Quarterly } & \multicolumn{7}{|c|}{ Monthly } \\
\hline Portfolios & Con. $(\%)$ & $R_{E W A}$ & $R_{G D P}$ & $R_{H M L}$ & $R^{2}$ & & Portfolios & Con. $(\%)$ & $R_{E W A}$ & $R_{G D P}$ & $R_{H M L}$ & $R^{2}$ & \\
\hline \multirow[t]{2}{*}{$P 1$} & -3.615 & 1.051 & 1.786 & -0.518 & 0.822 & & $P 1$ & -1.198 & 1.046 & 0.511 & -0.510 & 0.811 & \\
\hline & $(0.550)$ & $(0.051)$ & $(0.419)$ & $(0.037)$ & & & & $(0.193)$ & $(0.037)$ & $(0.142)$ & $(0.025)$ & & \\
\hline \multirow[t]{2}{*}{$P 2$} & -2.567 & 0.928 & 1.504 & 0.076 & 0.578 & & $P 2$ & -1.173 & 0.960 & 0.731 & 0.007 & 0.562 & \\
\hline & $(0.647)$ & $(0.061)$ & $(0.486)$ & $(0.039)$ & & & & $(0.240)$ & $(0.047)$ & $(0.175)$ & $(0.026)$ & & \\
\hline \multirow[t]{2}{*}{$P 3$} & 0.250 & 0.998 & -0.168 & -0.095 & 0.555 & & $P 3$ & 0.072 & 0.972 & -0.026 & -0.055 & 0.543 & \\
\hline & $(0.666)$ & $(0.062)$ & $(0.499)$ & $(0.044)$ & & & & $(0.279)$ & $(0.052)$ & $(0.201)$ & $(0.027)$ & & \\
\hline \multirow[t]{2}{*}{$P 4$} & 0.465 & 0.972 & 0.192 & 0.054 & 0.512 & & $P 4$ & 0.249 & 0.975 & -0.026 & 0.069 & 0.495 & \\
\hline & $(0.768)$ & $(0.076)$ & $(0.620)$ & $(0.059)$ & & & & $(0.249)$ & $(0.060)$ & $(0.197)$ & $(0.038)$ & & \\
\hline \multirow[t]{2}{*}{$P 5$} & 5.467 & 1.051 & -3.314 & 0.482 & 0.866 & & $P 5$ & 2.050 & 1.046 & -1.190 & 0.490 & 0.824 & \\
\hline & $(0.550)$ & $(0.051)$ & $(0.419)$ & $(0.037)$ & & & & $(0.193)$ & $(0.037)$ & $(0.142)$ & $(0.025)$ & & \\
\hline
\end{tabular}


Table 7

Descriptive statistics of the basis sorted portfolios

The table presents excess return characteristics of portfolios sorted on the futures basis at two frequencies: monthly (Panel A) and quarterly (Panel B). The portfolios are constructed so that $P 1$ contains the quintile of futures returns with the lowest basis, whereas $P 5$ contains the quintile of futures with the highest basis. EWA and HML are derived analogously to those in Table 1. Kurtosis represents the sample excess kurtosis relative to the normal distribution. The last row in each panel summarizes the correlations between the return on the basis portfolios and the corresponding portfolios from Table 1. The sample span is from December 1969 to December 2012 .

\begin{tabular}{lrrrrrrr}
\hline Statistic & $P 1$ & $P 2$ & $P 3$ & $P 4$ & $P 5$ & EWA & HML \\
\hline \multicolumn{7}{c}{ Panel A: Monthly returns } \\
\hline Mean & -4.314 & -0.234 & 5.300 & 9.759 & 14.405 & 4.983 & 18.720 \\
Median & -4.058 & -0.498 & 2.392 & 7.176 & 8.154 & 6.074 & 15.232 \\
Std. & 19.816 & 17.421 & 17.119 & 19.615 & 20.864 & 13.547 & 23.678 \\
Skewness & 0.691 & 0.266 & 0.113 & -0.241 & 0.941 & 0.172 & -0.071 \\
Kurtosis & 3.905 & 1.913 & 1.130 & 4.859 & 4.656 & 3.238 & 2.423 \\
SR & -0.218 & -0.013 & 0.310 & 0.498 & 0.690 & 0.368 & 0.791 \\
Corr. & 0.928 & 0.816 & 0.831 & 0.860 & 0.963 & 0.998 & 0.920 \\
\hline \multicolumn{7}{c}{ Panel B: Quarterly returns } \\
\hline Mean & -4.148 & -0.396 & 5.459 & 9.747 & 15.007 & 5.134 & 19.155 \\
Median & -8.160 & -0.475 & 2.433 & 11.343 & 11.235 & 5.700 & 19.584 \\
Std. & 20.390 & 16.394 & 18.035 & 19.488 & 23.696 & 13.951 & 28.158 \\
Skewness & 0.506 & 0.092 & 0.176 & -0.077 & 1.018 & -0.170 & 0.378 \\
Kurtosis & 2.609 & 0.486 & 1.518 & 1.201 & 3.515 & 1.446 & 5.056 \\
SR & -0.203 & -0.024 & 0.303 & 0.500 & 0.633 & 0.368 & 0.680 \\
Corr. & 0.937 & 0.807 & 0.829 & 0.853 & 0.971 & 0.997 & 0.941 \\
\hline
\end{tabular}




\section{Table 8}

\section{Descriptive statistics of the momentum portfolios}

The table presents excess return characteristics of momentum portfolios. Panel A summarizes the statistics at monthly frequency and Panel B at quarterly. The portfolios are constructed so that $P 1$ contains the quintile of futures with the lowest average return over the previous 12 months, whereas $P 5$ contains the quintile of futures with the highest average return over the previous 12 months. EWA and HML are derived analogously to those in Table 1. Kurtosis represents the sample excess kurtosis relative to the normal distribution. The last row in each panel summarizes the correlations between the return on the basis portfolios and the corresponding portfolios from Table 1. The sample span is December 1969 to December 2012.

\begin{tabular}{lrrrrrrr}
\hline Statistic & $P 1$ & $P 2$ & $P 3$ & $P 4$ & $P 5$ & EWA & HML \\
\hline \multicolumn{7}{c}{ Panel A: Monthly returns } \\
\hline Mean & -3.088 & 2.414 & 6.017 & 5.480 & 15.571 & 5.279 & 18.659 \\
Median & -6.744 & -1.549 & 6.200 & 3.321 & 11.614 & 5.435 & 18.983 \\
Std. & 20.293 & 16.493 & 16.205 & 18.464 & 25.104 & 13.867 & 27.723 \\
Skewness & 1.063 & 0.470 & 0.449 & 0.372 & 0.350 & 0.229 & 0.096 \\
Kurtosis & 5.176 & 2.350 & 2.242 & 3.884 & 3.820 & 3.480 & 0.768 \\
SR & -0.152 & 0.146 & 0.371 & 0.297 & 0.620 & 0.381 & 0.673 \\
Corr. & 0.638 & 0.528 & 0.593 & 0.551 & 0.631 & 0.996 & 0.353 \\
\hline \multicolumn{7}{c}{ Panel B: Quarterly returns } \\
\hline Mean & -3.231 & 2.661 & 6.272 & 5.602 & 15.897 & 5.44 & 19.128 \\
Median & -5.931 & 3.495 & 1.821 & 4.871 & 11.54 & 6.177 & 15.845 \\
Std. & 19.144 & 17.862 & 17.668 & 19.48 & 26.871 & 14.409 & 29.21 \\
Skewness & 0.204 & 0.115 & 0.215 & 0.973 & 0.947 & 0.003 & 0.253 \\
Kurtosis & -0.032 & 1.189 & 0.802 & 4.719 & 3.197 & 1.87 & 0.734 \\
SR & -0.169 & 0.149 & 0.355 & 0.288 & 0.592 & 0.378 & 0.655 \\
Corr. & 0.596 & 0.471 & 0.629 & 0.555 & 0.646 & 0.996 & 0.386 \\
\hline
\end{tabular}


Table 9

\section{Asset pricing results for portfolios sorted on basis and momentum}

Panel A reports the cross-sectional asset pricing results for the basis sorted portfolios. Panel B reports the corresponding results for the momentum based portfolios. The model specification is identical to that in Table 3. In both panels the parameters are estimated via GMM, with heteroscedasticity and autocorrelation consistent standard errors in parentheses. All estimates are reported in per cent. The $J$-statistic for the overidentifying restrictions is also reported, with the corresponding $p$-value in parentheses. MAE represents the cross-sectional mean absolute standard error.

\begin{tabular}{|c|c|c|c|c|c|c|c|c|c|c|c|}
\hline \multicolumn{12}{|c|}{ Panel A: Basis portfolios } \\
\hline \multicolumn{6}{|c|}{ Quarterly } & \multicolumn{6}{|c|}{ Monthly } \\
\hline GMM & $R_{E W A}$ & $R_{G D P}$ & $R^{2}$ & $J$ & MAE & GMM & $R_{E W A}$ & $R_{G D P}$ & $R^{2}$ & $J$ & MAE \\
\hline \multirow[t]{2}{*}{$b$} & 1.072 & -66.390 & 0.818 & 6.517 & 0.569 & $b$ & 1.464 & -85.736 & 0.787 & 4.822 & 0.203 \\
\hline & $(1.564)$ & $(19.614)$ & & $(0.089)$ & & & $(1.519)$ & $(20.501)$ & & $(0.185)$ & \\
\hline \multirow[t]{2}{*}{$\lambda$} & 1.230 & -0.771 & & & & $\lambda$ & 0.408 & -0.710 & & & \\
\hline & $(0.533)$ & $(0.208)$ & & & & & $(0.174)$ & $(0.165)$ & & & \\
\hline \multicolumn{12}{|c|}{ Panel B: Momentum portfolios } \\
\hline \multicolumn{6}{|c|}{ Quarterly } & \multicolumn{6}{|c|}{ Monthly } \\
\hline GMM & $R_{E W A}$ & $R_{G D P}$ & $R^{2}$ & $J$ & MAE & GMM & $R_{E W A}$ & $R_{G D P}$ & $R^{2}$ & $J$ & MAE \\
\hline \multirow[t]{2}{*}{$b$} & 0.208 & -99.412 & 0.938 & 0.942 & 0.321 & $b$ & 0.772 & -119.750 & 0.968 & 0.762 & 0.066 \\
\hline & $(2.010)$ & $(40.384)$ & & $(0.815)$ & & & (1.918) & $(43.337)$ & & $(0.859)$ & \\
\hline \multirow[t]{2}{*}{$\lambda$} & 1.233 & -1.138 & & & & $\lambda$ & 0.391 & -0.977 & & & \\
\hline & $(0.528)$ & $(0.428)$ & & & & & $(0.177)$ & $(0.347)$ & & & \\
\hline
\end{tabular}




\section{Figure 1}

Pricing error for the percentage net basis portfolios
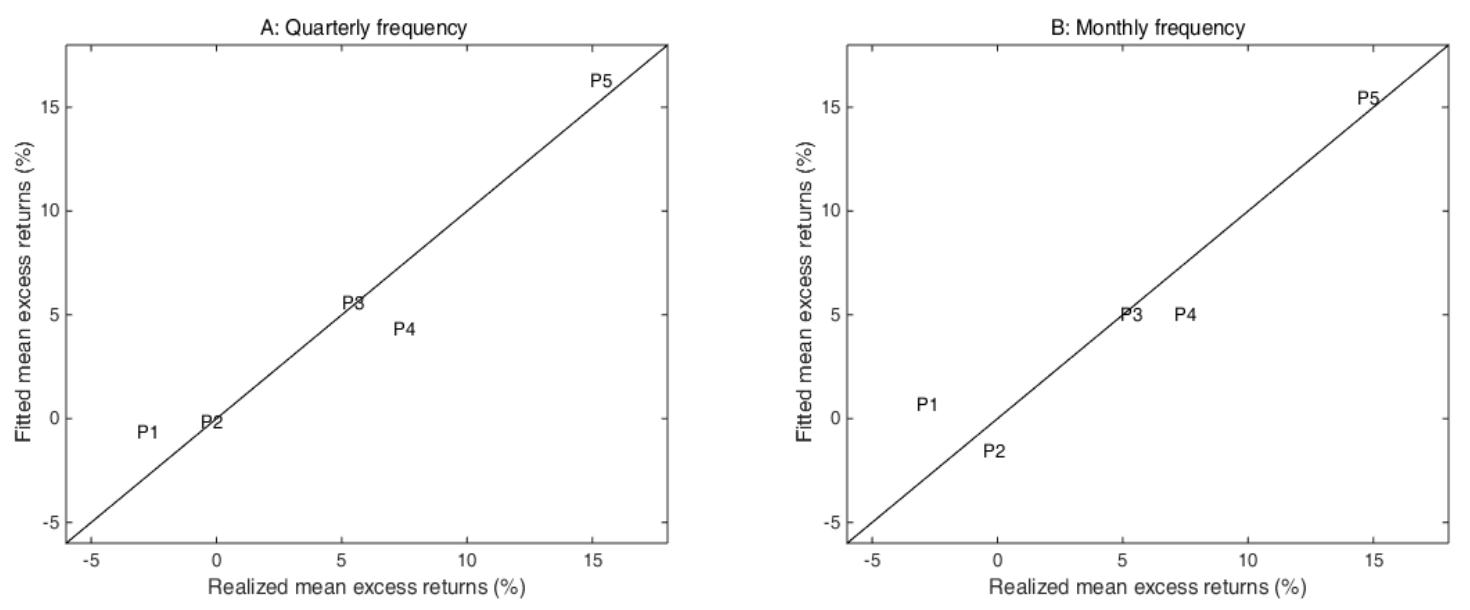

The figure shows the actual sample average excess returns (horizontal axis) on 5 futures portfolios sorted on the percentage net basis (see the text or notes to Table 1) versus the expected average excess returns (vertical axis) from a two factor asset pricing model. The first factor is an equally-weighted return from a long position in all percentage net basis portfolios, whereas the second factor is a factor-mimicking portfolio that captures news related to future GDP growth. The sample period is December 1969 to December 2012. 


\section{Figure 2}

Pricing error for the basis portfolios
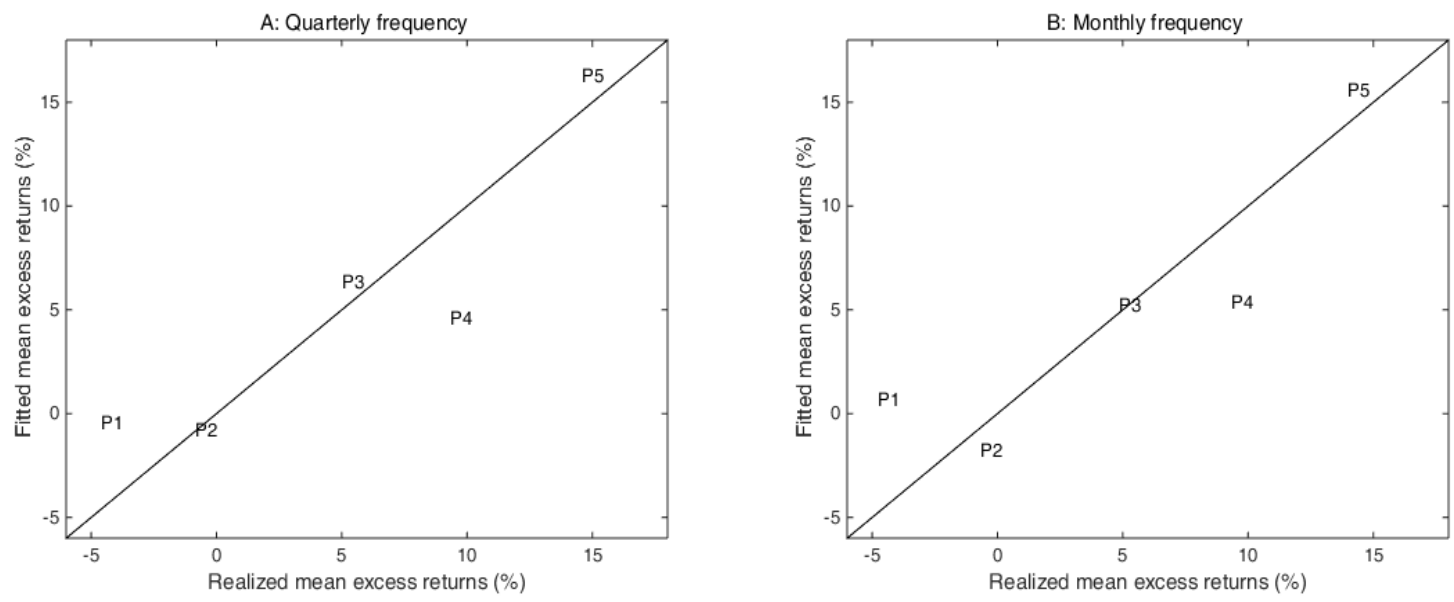

The figure shows the actual sample average excess returns (horizontal axis) on 5 futures portfolios sorted on the basis (see the text or notes to Table 7) versus the expected average excess returns (vertical axis) from the two factor asset pricing model (see notes to Figure 1). The sample period is December 1969 to December 2012. 


\section{Figure 3}

Pricing error for the momentum portfolios
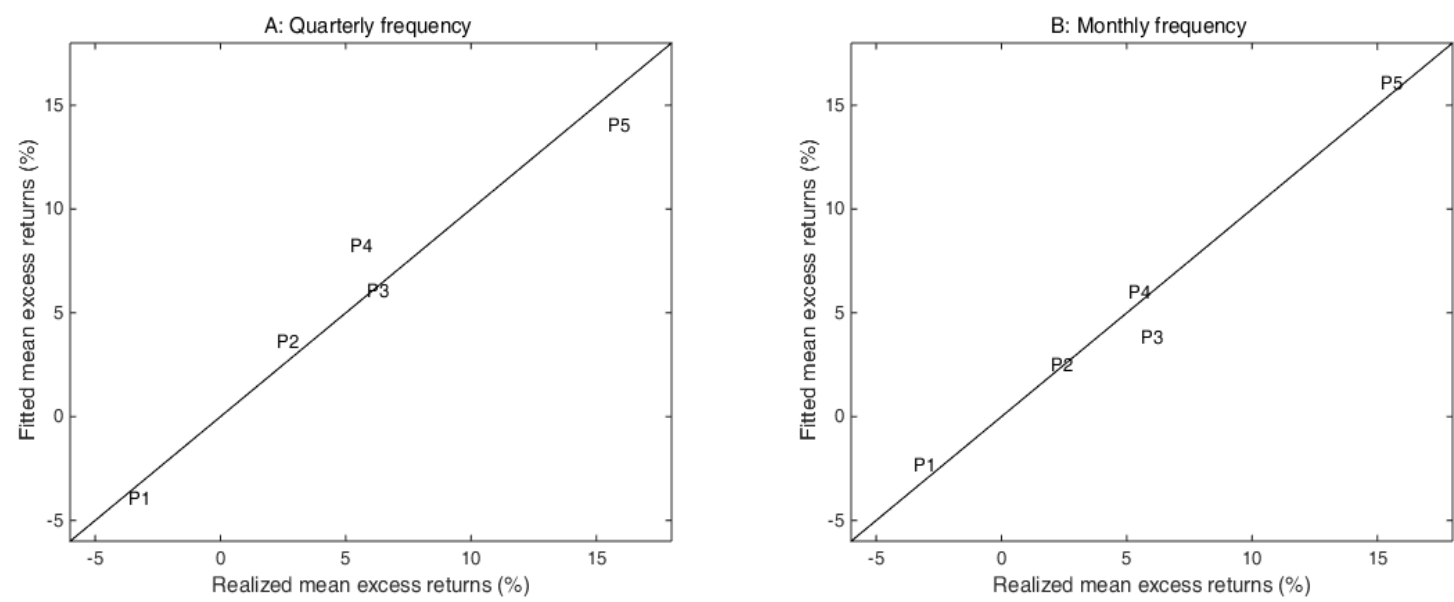

The figure shows the actual sample average excess returns (horizontal axis) on 5 futures portfolios sorted on the futures average excess return over the previous 12 months (see the text or notes to Table 8) versus the expected average excess returns (vertical axis) from the two factor asset pricing model (see notes to Figure 1). The sample period is December 1969 to December 2012. 